\title{
Assessment of problem solving proficiencies with self-efficacy perceptions of students in faculty of health sciences of cyprus international university
}

\author{
S.Yaprak Cetin $^{1, *}$, Suat Erel $^{2}$ and Ozge Ozalp ${ }^{3}$ \\ ${ }^{1}$ Akdeniz University, Department of Physiotherapy and Rehabilitation, Antalya, 70002, Turkey \\ ${ }^{2}$ Pamukkale Univesity, School of Physical Therapy and Rehabilitation, Denizli, 20160, Turkey \\ ${ }^{3}$ Cyprus International University, Health Sciences Faculty, Department of Physiotherapy and \\ Rehabilitation, Nicosia, 99258, Turkish Republic of North Cyprus
}

\begin{abstract}
The aim of this study is to evaluate the self-efficacy perceptions and problem solving competencies of students of Health Sciences Faculty. The study included 150 students studying in 4 th grade who completed the questionnaire completely. Self-efficacy-competence scale was used to evaluate students' self-efficacy perceptions, and Problem Solving Inventory was used to evaluate problem solving proficiencies. The mean age of the students included in the study was $22.26 \pm 1.27$ years and $59.3 \%[\mathrm{n}=89]$ were female students. It was determined that the self-efficacy perception scores of the students were $82.30 \pm 14.37$ and the problem solving ability scores were $103.65 \pm 19.31$. There was a significant relationship between self-efficacy perception and problem solving ability $[\mathrm{r}=-0,328, \mathrm{p}: 0.01]$. According to the results, it was determined that the students had a low level of self-efficacy perception and problem solving competencies.
\end{abstract}

Keywords: Student, Self-Efficacy ,Problem Solving, Health Sciences, Students

\section{Introduction}

Problem solving is "directing, respectively, the cognitive and effective behavioral activities such as giving behavioral reactions in order to adapt to complex internal and/or external wishes and desires" [1]. Problem solving competency involves many aspects including the self-belief of an individual in the cognitive process and problem solving.

The term self-efficacy was first introduced in 1977 by Bandura. Self-efficacy is described as a general capacity of an individual related to his/her belief of his/her competencies that can enable that individual to manage challenging situations that $\mathrm{s} / \mathrm{he}$ has encountered or may encounter and a general capacity which involves cognitive, social,

\footnotetext{
"Corresponding author: fzt_s.yaprakulgen@hotmail.com
} 
emotional and behavioral competencies and which has to be managed and organized for countless purposes [2]. A low perception of self-efficacy means the failure of an individual in believing his/her competencies and his/her perceiving challenges or tasks as problems. A high perception of self-efficacy, on the other hand, means considering the tasks with high levels of difficulty as opportunities that can be overcome, and thus managing to act more efficiently. Belief of self-efficacy has an influence on the way an individual thinks, feels, behaves and motivates himself/herself [2,3].

Regarding self-efficacy and learning strategies, Campbell and Hackett [1986], note that self-efficacy plays an important role in learning problem solving. The belief in self-efficacy can also influence the way individuals think as well as their emotional reactions. Individuals with low-self efficacy may tend to think that things are harder than they seem and may not be able to solve problems. Nevertheless, individuals with high self-efficacy approach more comfortably towards challenging tasks and problems and therefore can be more successful in solving the problems [4].

In literature, some studies have examined the perception of self-effectiveness/selfefficacy and problem solving proficiency separately and identified the factors determining these concepts. In literature, there is no study available that examines the self-efficacy/selfeffectiveness perception and problem solving proficiency of students studying at faculty of health sciences.

The aim of this study is to evaluate the self-efficacy perceptions and problem solving proficiencies of students in the last semester of Health Sciences Faculty in Cyprus International University. It also examines whether there is a relationship between selfefficacy perceptions and problem solving proficiencies.

\section{Method}

\subsection{Participants}

The population of the research comprises of the students receiving education at Cyprus International University, Faculty of Health Sciences. The criteria of inclusion in the research necessitate being enrolled in one of the departments of Physiotherapy and Rehabilitation, Nutrition and Dietetics and Nursing departments within the faculty of health sciences, as well as volunteering to participate. The criterion of non-inclusion is he/she filling out the questionnaire incompletely.

\subsection{Procedure}

Problem Solving Inventory was used to evaluate problem solving proficiencies. The scale was developed by Heppner and Peterson in 1982 and adapted to Turkish by Sahin et.al in $1999[5,6]$. This Likert type scale consisting of 35 items and 3 sub-dimensions [confidence in problem solving ability, approach-avoidance, personal control] scored between 1-6; the lowest 32, the highest 192 can be taken. The high score indicates that the individual perceives himself / herself inadequately in problem solving skills and the low score indicates that he / she perceives himself / herself more adequately in problem solving skills [6].

Self-efficacy competence scale was used to evaluate students' self-efficacy perceptions. The scale was developed by Sherer et al. in 1982 and adapted to Turkish by Gozum and Aksayan in 1999 [7,8]. The scale consists of 23 items and 4 sub-dimensions [starting, maintaining, completing and interfering with behavior]. This Likert type scale scored between 1-5; the lowest score is 23 , the highest score is 115 . High score indicates high self- 
efficacy-competence perception, low score low self-efficacy-competence perception [8].

\subsubsection{Statistical Analyses}

Data collected by researchers was analyzed in SPSS 16.0 [Statistical Package for Social Science for Windows] package. In the evaluation mean, standard deviation and frequency distribution statistics were used. The Kolmogorov Smirnov Test was used to determine whether the data suit the normal distribution. Spearman correlation analysis was used for relationship between self-efficacy perception and problem solving ability because the data didn't suit the normal distribution. The Kruskal-Wallis test was used to determine whether there was a difference between self-efficacy and problem-solving ability among the sections. Mann Whitney $U$ test was used in binary comparisons. Significance level was accepted as $\mathrm{p}<0.05$.

\section{Results}

The mean age of the students included in the study was $22.26 \pm 1.27$ years and $59.3 \%$ [n $=$ 89] were female students [Table 1].

Table 1. Demographic variables of students

\begin{tabular}{|c|c|c|}
\hline & $\mathbf{X} \pm$ SD & min-max \\
\hline Age [years] & $22.26 \pm 1.27$ & $21-27$ \\
\hline Weight (kg) & $62.07 \pm 13.09$ & $48-93$ \\
\hline Height (cm) & $168.53 \pm 11.14$ & $158-182$ \\
\hline Gender & $\mathbf{\%}$ & $\mathbf{n}$ \\
\hline Female & 59.3 & 89 \\
Male & 40.7 & 61 \\
\hline
\end{tabular}

It was found that the mean score of the self-efficiency/self-efficacy scale of students was $82.30 \pm 14.37$ and the mean score of the problem solving inventory was $103.65 \pm 19.31$. There was a significant relationship in the negative direction between self-efficacy perception and problem solving ability [Table 2, $\mathrm{p}<0.05$ ].

Table 2. Investigation of the relationship between problem solving proficiency and self-efficacy perception

\begin{tabular}{|c|c|}
\hline & $\begin{array}{c}\text { Problem Solving Inventory } \\
\mathrm{r}\left[\mathrm{p}^{*}\right]\end{array}$ \\
\hline Problem Solving Inventory [score] & - \\
\hline Self Efficacy Scale [score] & $\mathbf{- . 3 2 8}[\mathbf{0 . 0 1}]$ \\
\hline
\end{tabular}

*Spearman correlation analyses, $\mathrm{p}<0.05$

It was also found that there is no difference among the departments regarding problem solving proficiency and self-efficacy perception [Table $3, \mathrm{p}<0.05$ ]. 
Table 3. Comparison of problem solving proficiency and self-efficacy perception of departments

\begin{tabular}{|c|c|c|c|c|c|c|}
\hline & $\begin{array}{c}\text { Physiotherapy } \\
\text { and } \\
\text { Rehabilitation } \\
\mathrm{X} \pm \mathrm{SD}\end{array}$ & $\begin{array}{c}\text { Nutrition and } \\
\text { dietetics } \\
\mathrm{X} \pm \mathrm{SD}\end{array}$ & $\begin{array}{c}\text { Nursing } \\
\mathrm{X} \pm \mathrm{SD}\end{array}$ & $\chi^{\mathbf{2}}$ & $\mathbf{p}^{\mathbf{*}}$ & $\mathbf{p}^{* *}$ \\
\hline $\begin{array}{c}\text { PSI } \\
\text { [score] }\end{array}$ & $106.22 \pm 19.67$ & $103.56 \pm 19.44$ & $101.18 \pm 18.85$ & 2.166 & .339 & $.553^{\mathrm{a}}$ \\
\hline $\begin{array}{c}\text { SES } \\
\text { [score] }\end{array}$ & $84.80 \pm 15.13$ & $81.42 \pm 14.57$ & $80.70 \pm 13.30$ & 2.710 & .258 & $.388^{\mathrm{b}}$ \\
\hline
\end{tabular}

*Kruskal Wallis test, **Mann Whitney U test, X: mean, SD: standard deviation, PSI: problem solving inventory, SES: self efficacy scale, a: nutrition-physiotherapy, b: physiotherapy-nursing, c: nutritionnursing

\section{Discussion}

The results of the study revealed that students have low level of problem solving proficiency and medium level of self-effectiveness/self-efficacy perception. Additionally, it was observed that there is a low level of correlation between problem solving proficiency and self-efficacy perception. In our study, students' self-efficacy perception increases; they perceived themselves more adequately about problem solving skills/proficiencies. It was found that there is no difference among the departments in terms of problem solving proficiencies and self-efficacy perception.

In literature, problem solving proficiencies and self-efficacy perceptions of students studying in the field of health sciences have been examined separately. Students that were involved in these studies are more generally students from nursing departments [9-12]. Our study is significant in the way that it determines altogether the problem solving proficiencies and self-efficacy perceptions of students from 3 different departments at the same faculty and also examines the relationship between them.

In a study conducted among nursing students, it is underlined that problem solving proficiencies are critical in all stages of health care system. It is highlighted that the art of caring entails problem solving proficiency, which sets the basis for knowledge, skills, expertise and effective medical practices [9] Moshirabadi et.al. [2015] notes that in order to improve the problem solving proficiency, educators need to help students overcome their emotional and cognitive challenges [10]. The studies conducted with Nursing Department students through making use of the Problem Solving Inventory have revealed that students have medium level of problem solving proficiencies [10-14]. Moreover, in some of the studies, it was observed that the problem solving proficiencies improved from the first grade to the fourth grade $[10,15]$. However, in our study, it was found that the problem solving proficiencies of students from all grades were at a low level. The fact that our results were found to be different than those in the literature can be related to such emotional factors as the upbringing, cultural background and educational background of the students. In the literature, it is underlined that problem solving proficiencies can be influenced by such characteristics $[6,16]$.

The body of literature stresses that the beliefs of self-efficacy is practically important for health care workers and that it is also related to academic achievement [17]. Various methods have so far been used in the literature for the assessment of self-efficacy $[18,19,20]$. In a study that employed a different assessment method than our study, it was found that the self-efficacy of nursing students is at a high level [19]. In the study conducted by Orgun and Karaöz'ün with nursing students, the self-effectiveness/self- 
efficacy scale was used and it was observed that the self-efficacy of students was at a medium level [11]. In our study it was found that self-efficacy is at a medium level not only among nursing students but also among physiotherapy and rehabilitation, and nutrition and dietetics students.

In the literature, a study that evaluated the relation between problem solving proficiency and self-efficacy perception was not found. Bandura asserts that self-efficacy provides for effective problem solving. In a study, it is noted that the strategies for increasing selfefficacy could also help for the resolution of social problems [21]. In the study carried out with nursing students, it was also observed that there is a relation between academic selfefficacy perception and problem solving proficiency [22]. In a study conducted at the faculty of nursing, a positive, medium-level but statistically insignificant relation between post training problem-solving ability and self-efficacy has been found [23]. In our study, it was observed that the problem solving proficiencies and self-efficacy perceptions of the students that study at the physiotherapy and rehabilitation, nutrition and dietetics and nursing departments of the faculty of health sciences are related at a low level. As the students from all of the departments have low levels of problem solving proficiencies, we think that the relationship between problem solving proficiency and the perception of selfefficacy is at a low level.

The limitation of our study has been the fact that the study involved only the students from the $4^{\text {th }}$ grade. Another limitation is that we were unable to include equal number of male and female students. Future studies may examine the problem solving proficiencies and self-efficacy perception of equal numbers of male and female students starting from the first grade and extending to upper grades.

Starting from the first year, we think that effective learning strategies during the undergraduate education can bring these characteristics to a better level than the last class. According to these results, the self-efficacy perception of the same group of students and problem solving proficiencies evaluation of Physiotherapy and rehabilitation, Nutrition and dietetics and Nursing education in last year is recommended.

\section{References}

1. P.P. Heppner, C.E. Baker, Applications of the Problem Solving Inventory. Meas Eval Couns Dev. 29, 4, 229-241 [1997]

2. A. Bandura, Self-efficacy: toward a unifying theory of behavioral change. Psychol Rev. 84, 2, 191-215 [1977]

3. K. McLaughlin, M. Moutray, O. Muldoon, The role of personality ve self efficacy in the selection ve retention of successful nursing students: a longitudinal study. J Adv Nurs., 61, 2, 211-221 [2007].

4. N. K. Campbell, G. Hackett, The effects of mathematics task performance on math selfefficacy and task interest. J Vocat Behav 28, 2, 149-162 [1986]

5. P. P. Heppner, C. H. Petersen, The Development and Implications of a Personal Problem-Solving Inventory. J Couns Psychol. 29, 1, 66-75 [1982]

6. N. Sahin, N. Sahin, P. Heppner. Psychometric properties of the Problem Solving Inventory in a group of Turkish University Students. Cog Theo Res, 17, 4 [1993]

7. M. Sherer, J.M. Maddux, The self-efficacy scale: Construction and Validation. Psychol Rep, 51, 663-671 [1982]

8. S. Gozum, S. Aksayan. The reliability and validity of Turkish form of the self-efficacy scale. J Ataturk University School of Nursing, 2,1 [1999]

9. J.J. Wang, K. Lo, Chi-Hui, K. Ya, Lie, Problem solving strategies integrated into nursing 
process to promote clinical problem solving abilities of RN-BSN students. Nurse Educ Today, 24, 589-595 [2004].

10. Z. Moshirabadi, N.Seyedfatemi, L. Borimnejad, H. Haghani, The Perceived Problem Solving Skill of Iranian Nursing Students. Client-Centered Nursing Care, 1, 3 [2015]

11. F. Orgun, B. Karaoz, Epistemological beliefs and the Self-efficacy Scale in nursing students. Nurse Educ Today, 34, 6, 37-40 [2014]

12. W.H. Jun, Anger expression, self-efficacy and interpersonal competency of Korean nursing students. Int Nurs Rev. 63, 4, 539-546 [2016]

13. N. Cinar, C. Sözeri, S. Sahin, R. Cevahir R, M. Say, Problem solving skills of the nursing and midwifery students and influential factors Rev Eletr Enf. 12, 4, 601-606 [2010]

14. I. Altun, The perceived problem solving ability and values of student nurses and midwives, Nurse Educ Today, 23, 575-584 [2003].

15. M. Uslu, C. Girgina, Effects of residential conditions on the problem solving skils of university students Procedia Soc Behav Sci, 2 , 3031-3035 [2010]

16. P.P. Heppner, C.E. Baker, Applications of the Problem Solving Inventory. Meas Eval Couns Dev. 29, 4, 229-241 [1997]

17. J. Lane, A. Lane, Self-efficacy and academic performance. SBPJ. 29, 687-694 [2001]

18. A.E. Durkin, R.S. Feinn, Traditional and Accelerated Baccalaureate Nursing Students' Self-Efficacy for Interprofessional Learning. Nurs Educ Perspect. 38, 1, 23-28 [2017]

19. U. Karabacak, S. Serbest, Z. Kan Onturk, F. Eti Aslan, N. Olgun, Relationship between student nurses' self-efficacy and psychomotor skills competence. Int J Nurs Pract. 19, 2, 124-130 [2013].

20. S.L. Casapulla, Self-efficacy of Osteopathic Medical Students in a Rural-Urban Underserved Pathway Program. J Am Osteopath Assoc. 117, 9, 577-585 [2017]

21. A.D. Brown, M. L. Dorfman, C. R. Marmara, R.A. Bryant, The impact of perceived self-efficacy on mental time travel and social problem solving. Conscious Cogn, 21, 1, 299-306 [2012]

22. F.F. Zhao, X.L. Lei, W. He, Y.H. Gu, D.W. Li, The study of perceived stress, coping strategy and self-efficacy of Chinese undergraduate nursing students in clinical practice Int J Nurs Pract. 21, 401-409 [2015]

23. G. Angel, Problem solving training:effects on the problem solving skills and self efficacy of nursing students. Euro J Edu Res. 64, 231-246 [2016] 